\title{
High Rates of Interest in Sex in Patients With Hip Arthritis
}

\author{
Carlos J. Lavernia MD, Jesus M. Villa MD
}

Published online: 8 July 2015

(C) The Association of Bone and Joint Surgeons (R 2015

\begin{abstract}
Background Being sexually active has been associated with a high quality of life. Unfortunately, the topic of sexual limitations in patients undergoing total hip arthroplasty (THA) has not been well studied.

Question/purposes (1) What proportion of patients experience sexual limitations because of hip arthritis before THA; (2) whether patient reports of sexual limitations would be associated with poorer results on general health and hip-specific instruments; and (3) whether patient reports of sexual limitations would be associated with poorer preoperative range of motion.

Methods Between May 19, 2003, and August 17, 2009, 403 patients (423 hips) underwent primary THA; of those, 237 patients/hips (59\% [237 of 403]) had addressed the new patient questionnaire within 1 year before surgery and had it available for review; and of those, 192 (48\% [192 of 403]) had answered the question about sexual function on their questionnaire. This group included 159 patients who

One of the authors (CJL) certifies that he has or may receive royalty payments or benefits in an amount of USD 10,000 to USD 100,000 from Stryker (Mahwah, NJ, USA). He also owns stock in Johnson \& Johnson (New Brunswick, NJ, USA), Zimmer (Warsaw, IN, USA), Stryker (Mahwah, NJ, USA), Wright (Arlington, TN, USA), and Symmetry Medical (Warsaw, IN, USA).

All ICMJE Conflict of Interest Forms for authors and Clinical Orthopaedics and Related Research ${ }^{\mathbb{R}}$ editors and board members are on file with the publication and can be viewed on request. Each author certifies that his or her institution approved the human protocol for this investigation, that all investigations were conducted in conformity with ethical principles of research, and that informed consent for participation in the study was obtained.
\end{abstract}

\section{J. Lavernia ( () , J. M. Villa}

The Center for Advanced Orthopedics at Larkin Hospital, 7000

SW 62nd Avenue, Suite 600, South Miami, FL 33143, USA

e-mail: c@drlavernia.com were sexually active (82\% [159 of 192]). These patients were defined as our study cohort. Among them, 131 patients (82\% [131 of 159]) reported some degree of sexual limitations and 28 patients (18\% [28 of 159]) did not report limitations. Patient characteristics evaluated included baseline demographics, body mass index, American Society of Anesthesiologists, Charlson in addition to preoperative/postoperative pain intensity/frequency (visual analog scale, 0-10), SF-36, WOMAC, and baseline hip range of motion measures. Outcomes of interest were compared between both groups. Mean age was 65 years. Chi-square, t-tests, and multivariate analysis of variance were used. Alpha was set at 0.05 .

Results Hip arthritis interfered with the sexual life of $82 \%$ (131 of 159 ) of sexually active patients, more so in women than men (96\% [68 of 71], versus 72\% [63 of 88]; odds ratio, 8.99; 95\% confidence interval, 2.588-31.258; $\mathrm{p}=0.001)$. Preoperatively, patients with sexual limitations had a mean pain intensity of $8 \pm 1.84$ points on the visual analog scale, whereas patients without limitations had $6 \pm$ 1.99 points $(\mathrm{p}<0.001)$. Differences were also found in WOMAC pain $(11 \pm 3.9$ versus $8 \pm 3.5 ; \mathrm{p}=0.004)$ and WOMAC stiffness $(3.4 \pm 2.3$ versus $1.4 \pm 1.7$; $\mathrm{p}=0.001)$. Baseline hip flexion $\left(84^{\circ} \pm 22.4^{\circ}\right.$ versus $93^{\circ} \pm 16.5^{\circ}$, respectively; $\mathrm{p}=0.04)$ and external rotation $\left(23^{\circ} \pm 14.5^{\circ}\right.$ versus $30^{\circ} \pm 11.6^{\circ} ; \mathrm{p}=0.02$ ) were also different.

Conclusions Our data suggest that many patients getting a hip arthroplasty are sexually active but most patients who are sexually active have sexual limitations before surgery as a result of hip arthritis. Women are more affected than men. Patients with these limitations experience more pain and have less flexion and external rotation before surgery. Preoperatively, counseling on sexual activities should be routinely discussed with all patients undergoing THA.

Level of Evidence Level III, prognostic study. 


\section{Introduction}

Limitations in sexual activity are common among patients with hip arthritis [6] and patients often express that these issues can cause unhappiness or tension in their relationships $[6,10,16]$. Although patients frequently do not explicitly mention better sexual function as a desired result of surgery, many expect improvement after THA $[9,12,15]$.

Unfortunately, the sexual activities of patients are not addressed in most of the traditional hip scoring systems or self-assessment questionnaires currently in use [11]. Moreover, orthopaedic surgeons rarely discuss sexual activity with patients undergoing THA. In a survey of members of the American Association of Hip and Knee Surgeons performed by Dahm et al. [7], 80\% of surgeons reported that they rarely or never discuss sexual activity with their patients undergoing hip arthroplasty. Ninety-six percent of those surgeons who discussed the subject spent 5 minutes or less in such discussion. We therefore sought to gain a more complete picture of sexual function in prospective patients undergoing hip arthroplasty.

We sought to determine (1) what proportion of patients experience sexual limitations because of hip arthritis before THA; (2) whether patient reports of sexual limitations would be associated with poorer results on general health and hip-specific instruments; and (3) whether patient reports of sexual limitations would be associated with poorer preoperative (baseline) ROM.

\section{Patients and Methods}

In our institution, patients are routinely asked as part of our new patient intake questionnaire the following question: "How much does your hip or knee limit or interfere with your sexual activity?" Using our joint registry database, we retrospectively identified 403 patients (423 hips) who underwent primary THA performed by a single surgeon in a single institution between May 19, 2003, and August 17, 2009. Of those, 237 patients/hips (59\% [237 of 403]) had addressed the new patient questionnaire within 1 year before surgery and had it available for review, and of those, 192 (48\% [192 of 403]) had answered the specific question about sexual function on their questionnaire. This group included 159 patients who were sexually active (82\% [159 of 192]). These sexually active patients were defined as our study cohort. Among them, 131 patients (82\% [131 of 159]) reported some degree of sexual limitations and 28 patients (18\% [28 of 159]) did not report limitations. Revision cases with/without allograft were excluded. During the patient selection process, and in the presence of bilateral primary THAs, one hip was excluded. These two groups of sexually active patients ( 159 in total; limited $\mathrm{n}=131$ and not limited $\mathrm{n}=28$ ) were finally compared in the statistical analyses. We gathered baseline data on the study populations including baseline demographics such as age, gender as well as body mass index (BMI; $\mathrm{kg} / \mathrm{m}^{2}$ ), American Society of Anesthesiologist physical status (ASA) classification [1], and Charlson Comorbidity Index (CCI) [5].

The following preoperative and postoperative patientreported outcomes were included: pain intensity and frequency as measured by a visual analog scale (VAS) (range, 0-10), SF-36 [2] WOMAC [3] in addition to the following preintervention hip ROM measures: flexion, abduction, adduction, internal rotation, and external rotation performed by the authors using a goniometer. All data were prospectively collected in the joint registry database but it was retrospectively analyzed. In our institution, outcomes of interest are routinely assessed preoperatively and postoperatively at 3 months, 6 months, 1 year, and annually thereafter. Mean age was 65 years (range, 20-89 years). The minimum followup was 1 year (mean, 5 years; range, $1-10$ years).

\section{Statistical Analysis}

Chi-square, Fisher's exact test, and independent t-tests were used to determine whether baseline differences in demographics, BMI, and comorbidity scores existed between those patients with sexual limitations and those patients without limitations. Differences, if present, were used as covariates in further statistical analyses. Using the general linear model in SPSS (Version 16.0; IBM Corp, Armonk, NY, USA), a multivariate analysis of covariance was used to assess for differences between the two groups (sexually limited versus not limited) for all outcome measures (pain intensity/frequency VAS, SF-36, WOMAC, and hip ROM measures). A $\mathrm{p}$ value $\leq 0.05$ was considered statistically significant.

\section{Results}

We found that hip arthritis limited the sexual life of $82 \%$ (131 of 159) of those patients who ultimately underwent primary THA. Ninety-six percent (68 of 71) of women reported sexual limitations, whereas only $72 \%$ (63 of 88 ) of men did (odds ratio, 8.99; 95\% confidence interval [CI], 2.588-31.258; $\mathrm{p}=0.001)$. Age, BMI, and comorbidity scores (ASA, CCI) were not different between the two groups (Table 1).

Before surgery, patients with sexual limitations had inferior scores. Patients with sexual difficulties had a mean pain intensity as measured by the VAS of $8 \pm 1.84$ points, whereas patients without limitations had $6 \pm 1.99$ points (95\% CI, 0.8-2.5; $\mathrm{p}<0.001$ ). Pain frequency was $8 \pm 2.0$ 
Table 1. Demographics, body mass index, and comorbidities

\begin{tabular}{|c|c|c|c|}
\hline \multirow[t]{2}{*}{ Baseline patient characteristics } & \multicolumn{2}{|l|}{ Group } & \multirow[b]{2}{*}{$\begin{array}{l}\mathrm{p} \text { value } \\
(95 \% \mathrm{CI})\end{array}$} \\
\hline & Limited & Not limited & \\
\hline $\begin{array}{l}\text { Mean age (years) } \\
\text { (range, } 20-89 \text { ) }\end{array}$ & $65 \pm 12.5 \mathrm{SD}$ & $67 \pm 12.0 \mathrm{SD}$ & $\begin{array}{l}0.5 \\
(95 \% \mathrm{CI},-6.6 \text { to } 3.6)\end{array}$ \\
\hline \multicolumn{4}{|l|}{ Gender ( $\%$ within gender) } \\
\hline Women & $95.8(68 / 71)$ & $4.2(3 / 71)$ & $0.001 *$ \\
\hline Men & $71.6(63 / 88)$ & $28.4(25 / 88)$ & $(95 \%$ CI, 2.5-31.2) \\
\hline $\begin{array}{l}\text { Mean body mass index }\left(\mathrm{kg} / \mathrm{m}^{2}\right) \\
\text { (range, } 19.4-47.4)\end{array}$ & $28.6 \pm 4.8 \mathrm{SD}$ & $27.1 \pm 3.2 \mathrm{SD}$ & $\begin{array}{l}0.1 \\
(95 \% \mathrm{CI},-0.3 \text { to } 3.4)\end{array}$ \\
\hline $\begin{array}{l}\text { Mean Charlson Comorbidity Index } \\
\text { (range, 0-7) }\end{array}$ & $1.64 \pm 1.6 \mathrm{SD}$ & $1.54 \pm 1.6 \mathrm{SD}$ & $\begin{array}{l}0.7 \\
(95 \% \mathrm{CI},-0.5 \text { to } 0.7)\end{array}$ \\
\hline \multicolumn{4}{|l|}{ ASA grade ( $\%$ within ASA) } \\
\hline I & $100(2 / 2)$ & $0(0 / 2)$ & 0.8 \\
\hline II & $83.6(46 / 55)$ & $16.4(9 / 55)$ & (crosstabulation) \\
\hline III & $84.8(28 / 33)$ & $15.2(5 / 33)$ & \\
\hline IV & $100(1 / 1)$ & $0(0 / 1)$ & \\
\hline
\end{tabular}

* Statistically significant; alpha lower than 0.05; comparisons were made on available data; CI = confidence interval; ASA = American Society of Anesthesiologists physical status classification.

versus $6 \pm 2.4$, respectively $(95 \% \mathrm{CI}, 0.8-2.7$; $\mathrm{p}<0.001)$. Patients with limitations had more pain and stiffness on WOMAC subscores $(11 \pm 3.9$ versus $8 \pm 3.5$; $95 \% \mathrm{CI}$, $0.8-4.2 ; \mathrm{p}=0.004$ for pain; $3.4 \pm 2.3$ versus $1.4 \pm 1.7$; 95\% CI, 0.6-2.6; $\mathrm{p}=0.001$ for stiffness) and had worse scores on multiple sections of the SF-36 including the Physical Component Summary (Table 2). Postoperatively, all differences between the two groups disappeared with the exception of the SF-36 physical functioning score that remained worse in the group with sexual limitations at baseline $(51 \pm 22.0$ versus $67 \pm 16.2$, respectively; $95 \%$ CI, -21.2 to $-1.0 ; \mathrm{p}=0.031$ ) (Table 3 ).

With respect to the association between preoperative stiffness and sexual limitation, we found that patients who reported limitations had decreased hip flexion $\left(84^{\circ} \pm\right.$ $\left.22.4^{\circ}\right)$ and decreased hip external rotation $\left(23^{\circ} \pm 14.5^{\circ}\right)$ when compared with patients who did not report sexual limitations $\left(93^{\circ} \pm 16.5^{\circ}\right.$ and $30^{\circ} \pm 11.6^{\circ}$, respectively; $95 \% \mathrm{CI},-19.1$ to $-0.3 ; \mathrm{p}=0.043$ for hip flexion comparisons and $95 \% \mathrm{CI},-13.1$ to $-0.8 ; \mathrm{p}=0.02$ for hip external rotation comparisons) (Table 4).

\section{Discussion}

Difficulties having sex is a major factor that affects the quality of life of patients before undergoing THA [13, 15, 16]. Many patients attribute these difficulties to the underlying hip arthritis and expect an improvement in their sexual activities or participating in such activities as a result of their THA [9, 12, 15]. Unfortunately, this topic has been generally overlooked not only in the clinical practices of orthopaedic surgeons, but in the assessment tools and the hip arthroplasty literature in general $[7,8,11]$. Therefore, in the current investigation, we sought to determine (1) what proportion of patients experience sexual limitations because of hip arthritis before THA; (2) whether patient reports of sexual limitations would be associated with poorer results on general health and hip-specific instruments; and (3) whether patient reports of sexual limitations would be associated with poorer preoperative ROM.

Our results should be interpreted in light of several limitations. First, discussing sexual activity might have been uncomfortable for some patients and some indeed did not address the sexual question in the questionnaire. We based our study on those patients who actually addressed the single question and completely focused the analysis on the presence or not of sexual limitations among sexually active patients and their associations, if any, with scores. The baseline characteristics of the included patients coincide with those of patients routinely seen in this practice; as a consequence, we do not think that selection bias is present. Second, our sample was limited to a practice with a predominantly Hispanic population; consequently, the results might not be applicable for other patient groups without caution. Third, although data were collected prospectively, this is a retrospective observational study and consequently some of the differences observed could be the result of unaccounted variables. However, important characteristics known to influence outcomes such as basic demographics, BMI, and 
Table 2. Comparisons between the group with sexual limitations and the group without sexual limitations on preoperative patient oriented outcomes (gender was used as a covariate in multivariate tests)

\begin{tabular}{|c|c|c|c|}
\hline Dependent variable & Limited & Not limited & $\begin{array}{l}\mathrm{p} \text { value } \\
\text { (controlling by gender) } \\
(95 \% \mathrm{CI})\end{array}$ \\
\hline Pain VAS intensity & $8 \pm 1.8 \mathrm{SD}$ & $6 \pm 1.9 \mathrm{SD}$ & $\begin{array}{l}<0.001 * \\
(95 \% \mathrm{CI}, 0.8-2.5)\end{array}$ \\
\hline Pain VAS frequency & $8 \pm 2.0 \mathrm{SD}$ & $6 \pm 2.4 \mathrm{SD}$ & $\begin{array}{l}<0.001 * \\
(95 \% \mathrm{CI}, 0.8-2.7)\end{array}$ \\
\hline SF-36 Physical Functioning & $19 \pm 19.9 \mathrm{SD}$ & $44 \pm 28.1 \mathrm{SD}$ & $\begin{array}{l}<0.001 * \\
(95 \% \mathrm{CI},-28.5 \text { to }-9.7)\end{array}$ \\
\hline SF-36 Role Physical & $7 \pm 21.6 \mathrm{SD}$ & $19 \pm 37.0 \mathrm{SD}$ & $\begin{array}{l}0.05 \\
(95 \% \mathrm{CI},-22.4 \text { to }-0.006)\end{array}$ \\
\hline SF-36 Bodily Pain & $37 \pm 22.6 \mathrm{SD}$ & $56 \pm 20.0 \mathrm{SD}$ & $\begin{array}{l}0.002 * \\
(95 \% \mathrm{CI},-26.1 \text { to }-6.2)\end{array}$ \\
\hline SF-36 General Health & $75 \pm 20.8 \mathrm{SD}$ & $86 \pm 14.2 \mathrm{SD}$ & $\begin{array}{l}0.09 \\
(95 \% \mathrm{CI},-16.1 \text { to } 1.2)\end{array}$ \\
\hline SF-36 Vitality & $62 \pm 24.2 \mathrm{SD}$ & $75 \pm 16.8 \mathrm{SD}$ & $\begin{array}{l}0.1 \\
(95 \% \mathrm{CI},-18.1 \text { to } 2.0)\end{array}$ \\
\hline SF-36 Social Functioning & $44 \pm 33.9 \mathrm{SD}$ & $67 \pm 30.4 \mathrm{SD}$ & $\begin{array}{l}0.01 * \\
(95 \% \mathrm{CI},-33.3 \text { to }-3.7)\end{array}$ \\
\hline SF-36 Role Emotional & $73 \pm 42.4 \mathrm{SD}$ & $89 \pm 32.0 \mathrm{SD}$ & $\begin{array}{l}0.1 \\
(95 \% \mathrm{CI},-31.3 \text { to } 5.2)\end{array}$ \\
\hline SF-36 Mental Health & $70 \pm 20.5 \mathrm{SD}$ & $76 \pm 12.2 \mathrm{SD}$ & $\begin{array}{l}0.6 \\
(95 \% \mathrm{CI},-10.7 \text { to } 6.3)\end{array}$ \\
\hline $\begin{array}{l}\text { SF-36 Physical } \\
\text { Component Summary }\end{array}$ & $27 \pm 7.0 \mathrm{SD}$ & $35 \pm 9.1 \mathrm{SD}$ & $\begin{array}{l}<0.001 * \\
(95 \% \mathrm{CI},-10.0 \text { to }-3.4)\end{array}$ \\
\hline $\begin{array}{l}\text { SF-36 Mental } \\
\text { Component Summary }\end{array}$ & $54 \pm 11.8 \mathrm{SD}$ & $58 \pm 6.8 \mathrm{SD}$ & $\begin{array}{l}0.3 \\
(95 \% \mathrm{CI},-7.2 \text { to } 2.5)\end{array}$ \\
\hline WOMAC function & $40 \pm 12.7 \mathrm{SD}$ & $28 \pm 13.4 \mathrm{SD}$ & $\begin{array}{l}0.002 * \\
(95 \% \text { CI, 3.4-14.6) }\end{array}$ \\
\hline WOMAC pain & $11 \pm 3.9 \mathrm{SD}$ & $8 \pm 3.5 \mathrm{SD}$ & $\begin{array}{l}0.004 * \\
(95 \% \mathrm{CI}, 0.8-4.2)\end{array}$ \\
\hline WOMAC stiffness & $3.4 \pm 2.3 \mathrm{SD}$ & $1.4 \pm 1.7 \mathrm{SD}$ & $\begin{array}{l}0.001 * \\
(95 \% \mathrm{CI}, 0.6-2.6)\end{array}$ \\
\hline WOMAC total & $54 \pm 17.1 \mathrm{SD}$ & $37 \pm 15.5 \mathrm{SD}$ & $\begin{array}{l}<0.001 * \\
(95 \% \text { CI, 5.9-20.5) }\end{array}$ \\
\hline
\end{tabular}

$\bar{*} \mathrm{p}$ value $<0.05$ (multivariate analysis of covariance; gender was used as a covariate); $\mathrm{CI}=$ confidence interval; VAS $=$ visual analog scale.

comorbidities were included and analyzed. Furthermore, the comparisons between the two groups were made controlling for sex, which was the only baseline patient characteristic found significantly different between the two groups (sexually limited versus not limited). Finally, our measurements of hip ROM were done using a goniometer. It is known that goniometric measurements are not reproducible except within broad ranges and our differences may have been within measurement error. However, goniometric measurements are the ones routinely used in clinical practice. As a result, we do not think that this limitation invalidates the use of this tool in the current study.
We found that hip arthritis limited the sexual life of $82 \%$ (131 of 159) of patients and that women reported more problems in this regard than did men. Our findings confirm those of a limited number of publications addressing the sexual life of patients with hip arthritis. Currey [6], as early as 1970, provided information about the impact of hip arthritis on the sexual relationships of married couples. Through a questionnaire, the author found that $67 \%$ of patients experienced some degree of sexual difficulty as a result of their hip arthritis and that sexual difficulties were relatively more common and more severe among women than among men. Wall et al. [15] conducted a questionnaire 
Table 3. Comparisons between the group with sexual limitations and the group without sexual limitations on postoperative patient-oriented outcomes (gender was used as a covariate in multivariate tests)

\begin{tabular}{|c|c|c|c|}
\hline Dependent variable & Limited & Not limited & $\begin{array}{l}\mathrm{p} \text { value } \\
\text { (controlling by gender) }\end{array}$ \\
\hline Pain VAS intensity & $0.89 \pm 2.4 \mathrm{SD}$ & $0.86 \pm 2.1 \mathrm{SD}$ & $\begin{array}{l}0.9 \\
(95 \% \mathrm{CI},-1.1 \text { to } 1.2)\end{array}$ \\
\hline Pain VAS frequency & $0.92 \pm 2.5 \mathrm{SD}$ & $0.73 \pm 2.0 \mathrm{SD}$ & $\begin{array}{l}0.7 \\
(95 \% \mathrm{CI},-1.0 \text { to } 1.4)\end{array}$ \\
\hline SF-36 Physical Functioning & $51 \pm 22.0 \mathrm{SD}$ & $67 \pm 16.2 \mathrm{SD}$ & $\begin{array}{l}0.03^{*} \\
(95 \% \mathrm{CI},-21.2 \text { to }-1.0)\end{array}$ \\
\hline SF-36 Role Physical & $81 \pm 34.9 \mathrm{SD}$ & $98 \pm 10.6 \mathrm{SD}$ & $\begin{array}{l}0.08 \\
(95 \% \mathrm{CI},-29.3 \text { to } 1.8)\end{array}$ \\
\hline SF-36 Bodily Pain & $70 \pm 24.4 \mathrm{SD}$ & $80 \pm 17.2 \mathrm{SD}$ & $\begin{array}{l}0.3 \\
(95 \% \mathrm{CI},-16.3 \text { to } 5.8)\end{array}$ \\
\hline SF-36 General Health & $73 \pm 13.4 \mathrm{SD}$ & $77 \pm 6.1 \mathrm{SD}$ & $\begin{array}{l}0.3 \\
(95 \% \mathrm{CI},-8.9 \text { to } 3.2)\end{array}$ \\
\hline SF-36 Vitality & $69 \pm 12.9 \mathrm{SD}$ & $75 \pm 9.8 \mathrm{SD}$ & $\begin{array}{l}0.1 \\
(95 \% \mathrm{CI},-10.0 \text { to } 2.0)\end{array}$ \\
\hline SF-36 Social Functioning & $75 \pm 21.2 \mathrm{SD}$ & $88 \pm 13.5 \mathrm{SD}$ & $\begin{array}{l}0.06 \\
(95 \% \mathrm{CI},-18.7 \text { to } 0.4)\end{array}$ \\
\hline SF-36 Role Emotional & $96 \pm 18.0 \mathrm{SD}$ & $100 \pm 0.000 \mathrm{SD}$ & $\begin{array}{l}0.7 \\
(95 \% \mathrm{CI},-9.1 \text { to } 6.7)\end{array}$ \\
\hline SF-36 Mental Health & $76 \pm 11.6 \mathrm{SD}$ & $79 \pm 8.4 \mathrm{SD}$ & $\begin{array}{l}0.8 \\
(95 \% \mathrm{CI},-5.6 \text { to } 4.9)\end{array}$ \\
\hline $\begin{array}{l}\text { SF-36 Physical } \\
\text { Component Summary }\end{array}$ & $42 \pm 9.9 \mathrm{SD}$ & $48 \pm 4.4 \mathrm{SD}$ & $\begin{array}{l}0.05 \\
(95 \% \mathrm{CI},-8.7 \text { to } 0.07)\end{array}$ \\
\hline $\begin{array}{l}\text { SF-36 Mental } \\
\text { Component Summary }\end{array}$ & $56 \pm 6.1 \mathrm{SD}$ & $57 \pm 3.1 \mathrm{SD}$ & $\begin{array}{l}0.8 \\
(95 \% \mathrm{CI},-2.5 \text { to } 2.9)\end{array}$ \\
\hline WOMAC function & $4.39 \pm 7.5 \mathrm{SD}$ & $3.95 \pm 5.4 \mathrm{SD}$ & $\begin{array}{l}0.8 \\
(95 \% \mathrm{CI},-3.2 \text { to } 3.7)\end{array}$ \\
\hline WOMAC pain & $0.77 \pm 1.9 \mathrm{SD}$ & $0.68 \pm 1.6 \mathrm{SD}$ & $\begin{array}{l}0.8 \\
(95 \% \mathrm{CI},-0.8 \text { to } 1.0)\end{array}$ \\
\hline WOMAC stiffness & $0.19 \pm 0.6 \mathrm{SD}$ & $0.27 \pm 1.2 \mathrm{SD}$ & $\begin{array}{l}0.6 \\
(95 \% \mathrm{CI},-0.4 \text { to } 0.3)\end{array}$ \\
\hline WOMAC total & $5.35 \pm 9.6 \mathrm{SD}$ & $4.91 \pm 7.3 \mathrm{SD}$ & $\begin{array}{l}0.9 \\
(95 \% \mathrm{CI},-4.3 \text { to } 4.8)\end{array}$ \\
\hline
\end{tabular}

$* \mathrm{p}$ value $<0.05$ (multivariate analysis of covariance; gender was used as a covariate) $\mathrm{CI}=$ confidence interval; VAS = visual analog scale.

survey on 100 patients undergoing THA (immediately before and 6 months postoperatively) and found that among sexually active patients, $77 \%$ of them believed that their hip arthritis had been limiting their sexual lives. Stern et al. [13] evaluated 86 patients who had successful THA and, preoperatively, the authors found that $46 \%$ of patients attributed significant sexual difficulties to their hip pathology.

Our patients who reported difficulties with sex before THA consistently reported more pain from their arthritis than did patients without difficulties. Interestingly, however, the vitality and mental health scores as well as the mental component summary score of the SF-36 were no different between the two groups. These findings seem to be in agreement with the ones of Currey [6] who found that local mechanical factors were more important than any loss of sexual drive as a cause of sexual difficulty. In that study, $74 \%$ of patients attributed the sexual difficulty to stiffness, whereas $49 \%$ of them attributed it to pain. In our study, pain seemed to be the most important factor, in agreement with Wall et al. [15]. In that study, $77 \%$ of patients attributed the sexual difficulties to pain, whereas $27 \%$ of patients attributed those difficulties to restriction of motion. Postoperatively, we found that all differences between our 
Table 4. Comparisons between the group with sexual limitations and the group without sexual limitations on preintervention hip ROM (gender was used as a covariate in multivariate tests)

\begin{tabular}{|c|c|c|c|}
\hline Dependent variable & Limited & Not limited & $\begin{array}{l}\text { p value } \\
\text { (controlling by gender) } \\
(95 \% \mathrm{CI})\end{array}$ \\
\hline Hip flexion (mean) & $84^{\circ} \pm 22.4^{\circ} \mathrm{SD}$ & $93^{\circ} \pm 16.5^{\circ} \mathrm{SD}$ & $\begin{array}{l}0.043 * \\
(95 \% \mathrm{CI},-19.1 \text { to }-0.3)\end{array}$ \\
\hline Hip abduction (mean) & $32^{\circ} \pm 9.6^{\circ} \mathrm{SD}$ & $35^{\circ} \pm 9.2^{\circ} \mathrm{SD}$ & $\begin{array}{l}0.069 \\
(95 \% \mathrm{CI},-8.0 \text { to } 0.3)\end{array}$ \\
\hline Hip adduction (mean) & $24^{\circ} \pm 10.5^{\circ} \mathrm{SD}$ & $24^{\circ} \pm 9.6^{\circ} \mathrm{SD}$ & $\begin{array}{l}0.9 \\
(95 \% \mathrm{CI},-4.3 \text { to } 4.7)\end{array}$ \\
\hline Hip internal rotation (mean) & $12^{\circ} \pm 11.3^{\circ} \mathrm{SD}$ & $11^{\circ} \pm 12.4^{\circ} \mathrm{SD}$ & $\begin{array}{l}0.8 \\
(95 \% \mathrm{CI},-4.4 \text { to } 5.6)\end{array}$ \\
\hline Hip external rotation (mean) & $23^{\circ} \pm 14.5^{\circ} \mathrm{SD}$ & $30^{\circ} \pm 11.6^{\circ} \mathrm{SD}$ & $\begin{array}{l}0.027^{*} \\
(95 \% \mathrm{CI},-13.1 \text { to }-0.8)\end{array}$ \\
\hline
\end{tabular}

$* \mathrm{p}$ value $<0.05$ (multivariate analysis of covariance; gender was used as a covariate); $\mathrm{CI}=$ confidence interval.

two groups disappeared with the exception of the SF-36 physical functioning score, which remained worse in the group that reported sexual limitations. THA is highly effective in relieving pain and improving motion and previous reports have demonstrated that, for most patients, it is successful in the fulfillment of the sexual performance expectations or relieving sexual problems resulting from hip arthritis [10, 12-14].

We found that patients with sexual difficulties had slightly less hip flexion and external rotation before THA than did patients without such limitations. Our findings are in agreement with those of Charbonnier et al. [4] which used optical motion capture and MRI of two volunteers in vivo to determine the kinematics of the hip during sexual activity. Data were applied to prosthetic hip three-dimensional models to evaluate impingement and instability during motion. Twelve common sexual positions were performed, captured, and analyzed. The authors found that sexual positions for women require extreme hip ROM (high flexion combined with abduction and mostly external rotation), whereas sexual positions for men require less mobility but rely on pronounced external rotation. In our retrospective study, we found that hip flexion and hip external rotation were decreased in the group with sexual limitations, which might be supported by the findings of this motion capture study. The finding of Charbonnier et al. [4] that sexual positions in women require extreme hip ROM also might explain why women in our study reported more sexual limitations than men. Although we found differences in hip ROM between our two groups, the differences were not large and may have been within the range of measurement error for goniometrical measured hip ROM. For this reason, we believe that pain played a larger role in the sexual difficulties of our patients than did ROM.
In conclusion, we found that many patients undergoing THA are sexually active, but most patients have limitations in their sexual activities as a result of their hip arthritis. Women are more affected than men. There is increased pain and reduced flexion and external rotation among those patients who report sexual limitations. Sexual difficulties resulting from hip arthritis affect the quality of life of patients. Before surgery, counseling on sexual activities should be routinely discussed with all patients undergoing THA.

Acknowledgments We thank Mark D. Rossi PhD, PT, and Yohjan Suarez MD, for their technical support.

\section{References}

1. American Society of Anesthesiologists. ASA Physical Status Classification System. 2015. Available at: http://asahq.org/ resources/clinical-information/asa-physical-status-classificationsystem. Accessed February 10, 2015.

2. Arocho R, McMillan CA, Sutton-Wallace P. Construct validation of the USA-Spanish version of the SF-36 health survey in a Cuban-American population with benign prostatic hyperplasia. Qual Life Res. 1998;7:121-126.

3. Bellamy N, Buchanan WW, Goldsmith $\mathrm{CH}$, Campbell J, Stitt LW. Validation study of WOMAC: a health status instrument for measuring clinically important patient relevant outcomes to antirheumatic drug therapy in patients with osteoarthritis of the hip or knee. J Rheumatol. 1988;15:1833-1840.

4. Charbonnier C, Chague S, Ponzoni M, Bernardoni M, Hoffmeyer P, Christofilopoulos P. Sexual activity after total hip arthroplasty: a motion capture study. J Arthroplasty. 2014;29:640-647.

5. Charlson ME, Pompei P, Ales KL, MacKenzie CR. A new method of classifying prognostic comorbidity in longitudinal studies: development and validation. J Chronic Dis. 1987;40: 373-383.

6. Currey HL. Osteoarthrosis of the hip joint and sexual activity. Ann Rheum Dis. 1970;29:488-493. 
7. Dahm DL, Jacofsky D, Lewallen DG. Surgeons rarely discuss sexual activity with patients after THA: a survey of members of the American Association of Hip and Knee Surgeons. Clin Orthop Relat Res. 2004;428:237-240.

8. Frymoyer JW, Frymoyer NP. Physician-patient communication: a lost art? J Am Acad Orthop Surg. 2002;10:95-105.

9. Harris IA, Harris AM, Naylor JM, Adie S, Mittal R, Dao AT. Discordance between patient and surgeon satisfaction after total joint arthroplasty. J Arthroplasty. 2013;28:722-727.

10. Laffosse JM, Tricoire JL, Chiron P, Puget J. Sexual function before and after primary total hip arthroplasty. Joint Bone Spine. 2008;75:189-194.

11. Lieberman JR, Thomas BJ, Finerman GA, Dorey F. Patients' reasons for undergoing total hip arthroplasty can change over time. J Arthroplasty. 2003;18:63-68.
12. Mancuso CA, Jout J, Salvati EA, Sculco TP. Fulfillment of patients' expectations for total hip arthroplasty. J Bone Joint Surg Am. 2009;91:2073-2078.

13. Stern SH, Fuchs MD, Ganz SB, Classi P, Sculco TP, Salvati EA. Sexual function after total hip arthroplasty. Clin Orthop Relat Res. 1991;269:228-235.

14. Todd RC, Lightowler CD, Harris J. Low friction arthroplasty of the hip joint and sexual activity. Acta Orthop Scand. 1973;44: 690-693.

15. Wall PD, Hossain M, Ganapathi M, Andrew JG. Sexual activity and total hip arthroplasty: a survey of patients' and surgeons' perspectives. Hip Int. 2011;21:199-205.

16. Yoon BH, Lee KH, Noh S, Ha YC, Lee YK, Koo KH. Sexual activity after total hip replacement in Korean patients: how they do, what they want, and how to improve. Clin Orthop Surg. 2013;5:269-277. 